\title{
Rheological and Thermal Stability of Cationic-Modified Diutan Gum Biopolymer
}

(Reologi dan Kestabilan Terma Biopolimer Gam Diutan Diubahsuai Kationik)

\author{
Norhanis ArbaA' In, Rasidi Roslan*, IZAn Izwan Misnon \& MoHd Hasbi Ab RAhim
}

\begin{abstract}
Cationic diutan gum (CDG) biopolymer has been developed by incorporating a quaternary amine group on diutan gum (DG) structure to improve the thermal and rheological properties. The modification was performed by mixing DG with different $\mathrm{N}$-(3-chloro-2-hydroxypropyl) trimethyl ammonium chloride (CHPTAC) concentration to produce CDG in the presence of sodium hydroxide. The FTIR results confirmed the incorporation of cationic moieties onto the CDG chains. The surface morphology observed through FESEM showed that the smooth surface of DG was converted to a connective spherical reticular structure upon CHPTAC modification. The viscosity of CDG gelling fluid was increased after modification due to electrostatic chain interaction. Rheological properties showed that the plateau-like region was observed which signifying a stable gel response towards frequency. Thermal stability analysis using static thermal aging test showed the CDG was stable up to $170{ }^{\circ} \mathrm{C}$ suggesting this biopolymer can withstand the high-temperature requirements of the upstream petroleum industry.
\end{abstract}

Keywords: Cationized polysaccharide; CHPTAC; diutan gum; petroleum industry; rheological behavior

ABSTRAK

Biopolimer gam diutan berkation (CDG) telah dibangunkan dengan menggabungkan kumpulan amina kuaterner pada struktur gam diutan (DG) untuk menambahbaik sifat terma dan reologi. Pengubahsuaian dilakukan dengan mencampurkan DG dengan N-(3-kloro-2-hidroksipropil) trimetil ammonium klorida (CHPTAC) pada kepekatan yang berbeza untuk menghasilkan CDG dengan kehadiran natrium hidroksida. Keputusan FTIR mengesahkan penggabungan moieti berkation ke rantai CDG. Morfologi permukaan yang dicerap menggunakan FESEM menunjukkan bahawa permukaan licin DG ditukarkan kepada struktur sfera retikulum berhubung setelah pengubahsuaian CHPTAC dilakukan. Kelikatan bendalir pengegelan CDG meningkat selepas pengubahsuaian disebabkan oleh interaksi rantai elektrostatik. Sifat reologi menunjukkan lengkung dataran telah diperhatikan, menandakan tindak balas gel yang stabil terhadap frekuensi. Analisis kestabilan terma menggunakan ujian penuaan haba statik menunjukkan CDG stabil sehingga $170^{\circ} \mathrm{C}$ mencadangkan biopolimer ini mampu menampung keperluan suhu-tinggi industri petroleum huluan.

Kata kunci: CHPTAC; gam diutan; industri petroleum; penkationan polisakarida; tingkah laku reologi

\section{INTRODUCTION}

In the upstream petroleum industry, assistive-fluids such as drilling, fracturing, and completion fluids are generally injected into the petroleum reservoir for oil exploration and production. A thickening agent such as polymers are usually used to produce the assistive-fluids by dissolving the polymer in either water, monovalent, or divalent brines base fluid (Zhou et al. 2015). The most extensively used polymer for this application is synthetic hydrolyzed polyacrylamides (HPAMs) due to its availability and ability to be custom-made into desired molecular weight as well as variation in the degree of hydrolysis. However, the usage of these synthetic polymers is vulnerable to reservoir temperature and salinity due to the amide functional group hydrolysis rate increment producing more acrylic acid on the HPAM backbone which leads to the loss of thickening ability ( $\mathrm{Pu}$ et al. 2018). It is reported that at $50^{\circ} \mathrm{C}$ with the presence of divalent ions, the HPAM hydrolysis rate was prolonged. At $60-70{ }^{\circ} \mathrm{C}$, the hydrolysis rate was moderate and turned to rapid as the temperature increased to $90{ }^{\circ} \mathrm{C}$ (Ryles 1988). Due to this issue, various efforts have been made to develop polymers that are eco-friendly and able to withstand the high temperature and salinity requirements of the upstream petroleum industry.

Currently, biopolymers have been the focus owing to its environmental feature and superior tolerance to temperature and salinity. Biopolymers are usually having a distinctive linear structure, double or triple helical 
structure, rigidity and charge-free chains which enhance the thickening capability and stability in severe reservoir conditions. Various biopolymers have been studied including hydroxyethylcellulose (HEC) (Abbas et al. 2013), carboxymethylcellulose (CMC) (Marques et al. 2018), guar gum (GG) (Wang et al. 2015) hydroxypropyl guar (HPG, xanthan gum (XG) (Jang et al. 2015), welan gum (WG) (Arbaa'in et al. 2020; Gao 2016), and scleroglucan (Fariña et al. 2001). HEC and CMC are usually used for low-temperature applications $\left(<90{ }^{\circ} \mathrm{C}\right)$ as the apparent viscosity decreased to below $10 \mathrm{cP}$ (Bai et al. 2018). Meanwhile, for XG, WG, and scleroglucan, the fluid can withstand temperature up to $100-120{ }^{\circ} \mathrm{C}$ (Castillo et al. 2015; Gao 2015; Li et al. 2017). Among these biopolymers, XG has been the most extensively studied as drilling, fracturing, and pipeline cleaning fluid. XG fluid exhibits a pronounced shear-thinning behavior with a low power-law index due to the molecule aggregation through hydrogen bonding and biopolymer entanglement, which improve injectability for field operation (Pu et al. 2018). However, the application of commercial biopolymers was limited since the oil and gas exploration moving toward the hightemperature (above $120^{\circ} \mathrm{C}$ ) reservoir condition (Barnes et al. 2008). Therefore, finding a new biopolymer which can endure high temperature and salinity are necessary.

Diutan gum (DG) is a high molecular weight bacterial polysaccharide produced through aerobic fermentation of Sphingomonas sp. It is an anionic biopolymer which consists of a repeating unit of $\beta$-1,3-D-glucopyranosyl, $\beta$-1,4-L-glucuronopyranosyl, $\beta$-1,4-D-glucopyranosyl, and $\alpha-1,4-1-$ rhamnopyranosyl, and a two saccharide L-rhamnopyranosyl side-chain attached to the $(1 \rightarrow 4)$ linked glucopyranosyl residue (Banerjee et al. 2009; Sonebi \& McKendry 2008). Currently, DG is primarily applied in the cement and concrete industries. The DG has been used as a viscosity modifying agent in cement slurries because of its effectiveness in controlling bleeding by the formation of a viscous gel (Sonebi 2006; Zhang et al. 2010). Typically, the DG will act as a thickening, binding, emulsifying, suspending, and stabilizing agent when applied in specific applications. However, the study of DG for the upstream petroleum industry has rarely been reported. An exciting investigation of DG rheological properties has been reported (Xu et al. 2015). Their findings showed that DG gelling fluid could be produced at a very low concentration $(0.12 \mathrm{~g} / \mathrm{L})$. Besides, the gelling fluid is stable towards temperature range from $25-75{ }^{\circ} \mathrm{C}$ and virtually independent to the cationic environment $\left(\mathrm{Na}^{+}\right.$and $\left.\mathrm{Ca}^{2+}\right)$ due to its perfect double helix molecular conformation. In another study, the DG biopolymer was found insensitive toward salt and shearing time when compared with HPAM. The viscosity was stable after 90 days of aging at $85^{\circ} \mathrm{C}$, and $16 \%$ of oil recovery was obtained in the core flooding test (Liang et al. 2019). As the current state-of-art has proved that DG possessed excellent rheological properties, a question arises as to whether surface functionalization on DG will further progress or deteriorate its properties.

Several techniques have been previously conducted to modified polysaccharides such as nonionic (Wang et al. 2011), anionic (Tarus et al. 2014), and cationic (Prado \& Matulewicz 2014) modifications. Cationization of polysaccharide has been widely conducted to improve the properties of the polysaccharide. The modification of cationic moiety with anionic biopolymers can generate inter-polyelectrolyte complexes with hydrogel-like structures, expanding the former utilization. Until now, several chemical modifications involving the cationic moiety were performed on polysaccharide. For examples, cationic dextran was used in clay suspension separation (Ghimici et al. 2009), cationization on starch and konjac glucomannan as flocculating agent (Kavaliauskaite et al. 2008; Pal et al. 2005; Tian et al. 2010; Yu et al. 2007), study on the quaternized chitin (Chen et al. 2010), GG as a flocculating agent and for fine coal suspension (Pal et al. 2007), structural and rheological properties of kappa

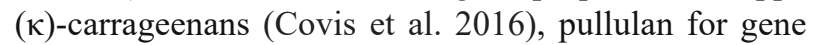
transfection carrier (Jo et al. 2010), and XG as thickener and stabilizer of emulsion (Shi et al. 2017). N-(3-chloro-2hydroxypropyl) trimethyl ammonium chloride (CHPTAC) or known as liquid cationic etherification agent, has been commonly deployed to enhance the properties of polysaccharides because of their stability and non-toxicity (Moral et al. 2016; Prado et al. 2011). The cationization reaction using CHPTAC generally begins with the formation of alkoxide on the polysaccharide hydroxyl group in the presence of $\mathrm{NaOH}$ (or other bases) aqueous solution. The alkoxide will then attacks the epoxide on the quaternary amine group of CHPTAC formed in-situ by the alkaline medium, and it opens the epoxide to form the hydroxy ether (Prado \& Matulewicz 2014). Recently, cationic XG has been synthesized by Shi et al. (2017) to enhance its rheological property by attaching quaternary amine groups to the XG backbone. Their results showed that viscosity, elastic and viscous modulus, and thermal stability were significantly improved compared with bare XG.

In the current study, the cationic diutan gum (CDG) was prepared by quaternary amine groups from CHPTAC grafting on the hydroxyl groups of DG. The effectiveness of cationic moiety modified on DG was studied by calculating the degree of substitution (DS), Fourier transform infrared (FTIR), and CHNS, while the surface morphology was observed using field emission scanning electron microscope (FESEM). Furthermore, the rheological properties (viscosity, elastic, and loss modulus) and thermal stability of the gelling fluid produced using DG and CDG were also investigated using rheometer and static thermal aging test, respectively.

\section{EXPERIMENTAL DETAILS MATERIAL}

The DG was supplied by Permula Chemicals Sdn Bhd. An aqueous solution of CHPTAC (60 wt. \%), sodium hydroxide $(\mathrm{NaOH})$, sodium chloride 
$(\mathrm{NaCl})$, absolute ethanol and $95 \%$ ethanol were purchased from Sigma Aldrich. All chemicals were used without any purification.

\section{CATIONIC MODIFICATION OF DIUTAN GUM (CDG)}

The cationization of DG was conducted by reacting DG with a cationic CHPTAC monomer. The procedure to prepare CDG is described as follows: $30 \mathrm{~g}$ of DG was dispersed in $100 \mathrm{~mL}$ of ethanol-water solution (the mass fraction of ethanol is $85 \%$ ). The solution was then mixed with $2.5 \mathrm{~mL}$ of $40 \mathrm{wt}$ \% $\mathrm{NaOH}$ aqueous solution to control the $\mathrm{pH}$ of the mixture. The mixture was stirred at ambient temperature for $40 \mathrm{~min}$. Afterward, a different amount of CHPTAC $(0.5-4 \mathrm{~mL})$ was added into the mixture and stirred at $70{ }^{\circ} \mathrm{C}$ for $2 \mathrm{~h}$ for the cationization process. Then, the mixture was cooled to room temperature and washed thoroughly with absolute ethanol. The CDG powder is finally obtained after drying at $80{ }^{\circ} \mathrm{C}$ overnight and labeled CDG1 - CDG6, as summarized in Table 1.

\section{DETERMINATION OF DS BY ELEMENTAL ANALYSIS}

The elemental analyses (carbon, hydrogen, nitrogen, and sulfur) of the DG and CDG were performed on CHNS elemental analyzer (EQPCL 200 Elementar, Germany, Vario Macro Cube). The DS was determined by elemental analysis of nitrogen. The following equation which was adapted from Haack et al. (2002) and Prado et al. (2011) was used to calculate the DS:

$$
D S=\frac{(403 \times \% N)}{1400-(152 \times \% N)}
$$

where 403 is the molecular weight of the average unit of DG. $\% N$ is the percentage of nitrogen on a dry basis. 1400 is the 100 times the mass of nitrogen and 152 is the molecular weight of the cationic substituting group.

\section{DG AND CDG POWDER CHARACTERIZATIONS}

The FTIR spectra of the DG and CDG powder were recorded using Spectrum One (Perkin Elmer, USA) using $\mathrm{KBr}$ technique. The pallet was scanned with resolution 2 $\mathrm{cm}^{-1}$ at wavenumber 4000 to $600 \mathrm{~cm}^{-1}$. The morphology of the DG and CDG were examined using FESEM (JEOL) at an accelerating potential of $5 \mathrm{kV}$. Thermogravimetric analysis (TGA) was performed using a Mettler Toledo, Switzerland thermal analyzer. Approximately $2 \mathrm{mg}$ of powder was placed in a platinum crucible and subjected to heating from 25 to $600{ }^{\circ} \mathrm{C}$ in a nitrogen atmosphere with a heating rate of $10{ }^{\circ} \mathrm{C} / \mathrm{min}$. The glass transition temperature $(\mathrm{Tg})$ of the powder was determined using Netzsch Polyma 214 differential scanning calorimetry (DSC). The DG and CDG were heated at a temperature from 25 to $200{ }^{\circ} \mathrm{C}\left(10{ }^{\circ} \mathrm{C} / \mathrm{min}\right)$ under a constant flow of nitrogen gas $(40 \mathrm{~mL} / \mathrm{min})$.

\section{PREPARATION OF DG AND CDG GELLING FLUID}

The gelling fluid was prepared by mixing $2.4 \mathrm{~g}$ DG or CDG powder in $500 \mathrm{~mL}$ of $2 \mathrm{wt} . \% \mathrm{NaCl}$ brine solution.
The solution was stirred using IKA RW20 overhead stirrer at $2000 \mathrm{rpm}$ in a $1 \mathrm{~L}$ beaker for $3 \mathrm{~h}$ at ambient temperature to achieve a homogeneous solution. The gelling fluid was kept stationary for overnight to eliminate bubbles formation.

\section{RHEOLOGICAL ANALYSIS OF DG AND CDG GELLING FLUID}

The rheological properties (viscosity and viscoelasticity) of DG and CDG fluid were determined via Malvern Kinexus Lab + rheometer using plate and plate geometry. In order to measure the apparent viscosity of the fluids, a plate and cone-plate have been used at a shear rate of 170 $\mathrm{s}^{-1}$ at ambient temperature. The viscoelasticity of fluids was determined by determining the linear viscoelastic region (LVER) through stress sweep testing in the range 0.01 to $300 \mathrm{~Pa}$ at a frequency of $1 \mathrm{~Hz}$. A frequency sweep testing is conducted from 0.1 to $10 \mathrm{~Hz}$ within the indicated LVER region.

\section{THERMAL STABILITY OF DG AND CDG GELLING FLUID USING STATIC THERMAL AGING TEST}

The thermal stability was performed by pouring the gelling fluid (80\% of the Teflon liner capacity) in closedsystem autoclave steel. The autoclave steel was inserted in an oven at ambient temperature and heated at a targeted temperature $\left(100-180{ }^{\circ} \mathrm{C}\right.$ ) for $1 \mathrm{~h}$. The gelling fluid was then cooled to room temperature, and the initial and final viscosity of the gelling fluid was determined at a shear rate of $170 \mathrm{~s}^{-1}$.

\section{RESULTS AND DISCUSSION}

\section{DS FROM ELEMENTAL ANALYSIS}

The elemental analysis result and the DS of DG and CDG are presented in Table 1. The elemental analysis result showed that there are no significant changes in the percentage of carbon $(\% \mathrm{C})$. As the cationization reaction using CHPTAC begins with the formation of alkoxide on the polysaccharide hydroxyl group (Figure 1(a)), it is expected the percentage of hydrogen $(\% \mathrm{H})$ will decrease. This can be seen when the $\% \mathrm{H}$ decreases from 5.54 to $3.81 \%$ as the CHPTAC concentration increased. The alkoxide will then attack the epoxide on the CHPTAC formed in situ by the alkaline medium, open the epoxide ring to form the hydroxy ether and grafted on the DG structure (Figure 1(b)). Nitrogen was not observed in the DG sample. However, after underwent cationization, the percentage of nitrogen $(\% \mathrm{~N})$ was increasing from 0.72 to 0.83 , showing that CHPTAC has been grafted in the CDG structure. Calculating the DS using the $\% \mathrm{~N}$ also creates a similar trend, which increases from $0.23-0.26$ but not significant compared to the result reported by Prado et al. (2011). This could be due to the insufficient $\mathrm{NaOH}$ because an equivalent of $\mathrm{NaOH}$ is necessary for generating the epoxide on CHPTAC. Moreover, $\mathrm{NaOH}$ is also required to ionize the hydroxyl groups on the DG structure, which are the nucleophiles of the reaction. 
TABLE 1. CHNS data, DS and viscosity of DG and CDG gelling fluid

\begin{tabular}{ccccccc}
\hline & $\begin{array}{c}\text { CHPTAC } \\
(\mathrm{mL})\end{array}$ & $\mathrm{C}($ wt. \%) & H (wt. \%) & $\mathrm{N}($ wt. \%) & DS & Viscosity (cP) \\
\hline DG & 0 & 38.45 & 4.27 & 0 & 0 & 104 \\
CDG1 & 0.5 & 38.32 & 5.54 & 0.72 & 0.23 & 115 \\
CDG2 & 1.0 & 38.05 & 5.55 & 0.73 & 0.23 & 112 \\
CDG3 & 1.5 & 38.61 & 4.03 & 0.75 & 0.24 & 102 \\
CDG4 & 2.0 & 38.35 & 4.08 & 0.77 & 0.24 & 80 \\
CDG5 & 3.0 & 37.56 & 3.93 & 0.80 & 0.25 & 60 \\
CDG6 & 4.0 & 38.22 & 3.81 & 0.83 & 0.26 & 48 \\
\hline
\end{tabular}
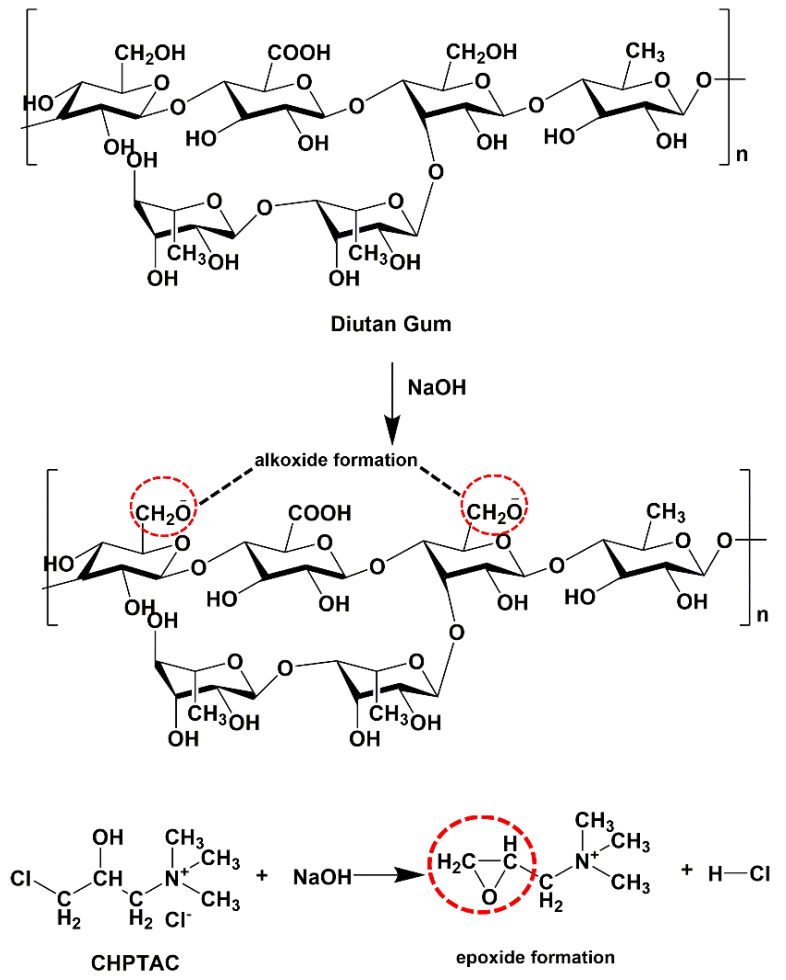

(b)

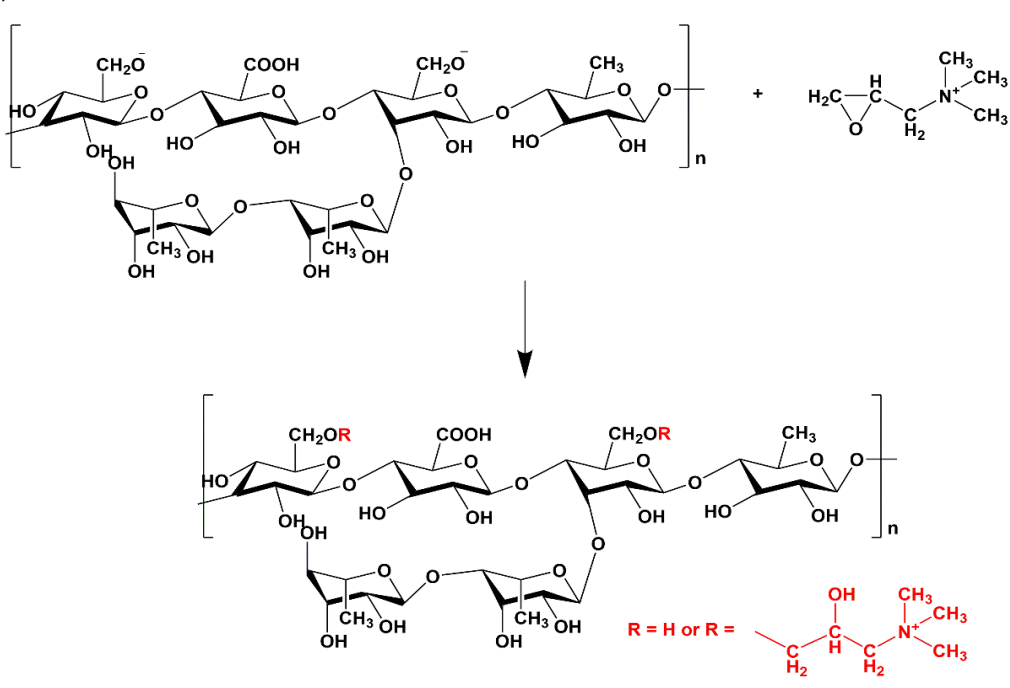

Cationic Diutan Gum

FIGURE 1. Schematic representation for the CDG synthesis; (a) activation with $\mathrm{NaOH}$, (b) reaction of DG with CHPTAC 
FUNCTIONAL GROUP ANALYSIS ON DG AND CDG VIA FTIR

Figure 2 illustrates the FTIR spectra of DG and CDG synthesized with different CHPTAC concentrations. The band centered at $3420 \mathrm{~cm}^{-1}$ was attributed to the stretching vibration of $\mathrm{O}-\mathrm{H}$ groups on the DG and CDG backbone. The peak at 2934 and $2885 \mathrm{~cm}^{-1}$ corresponded to the asymmetric and symmetric stretching vibration of $\mathrm{C}-\mathrm{H}$. The significant band at $\sim 1730 \mathrm{~cm}^{-1}$ is attributed to the adsorption of the $\mathrm{C}=\mathrm{O}$ bonds in the acetyl groups (Diltz \& Zeller 2001). The $\mathrm{C}-\mathrm{C}$ and $\mathrm{C}-\mathrm{O}$ stretching vibration can be observed at approximately 1600 and $1000 \mathrm{~cm}^{-1}$, respectively ( $\mathrm{Xu}$ et al. 2019)diutan gum (DG. Cationic modification on DG using CHPTAC has led to some significant changes in the original DG spectrum. First, the intensity of the $\mathrm{O}-\mathrm{H}$ peak was slightly decreasing after the cationic modification due to the substitution of a quaternary amine group on the hydroxyl group of DG. It is observed that the peak intensity at $1259 \mathrm{~cm}^{-1}$ was increasing resulted from the new $\mathrm{C}-\mathrm{O}$ bond formed between $\mathrm{DG}$ and CHPTAC. Besides, the appearance of a new peak at 1406 $\mathrm{cm}^{-1}$ is attributed to the $\mathrm{C}-\mathrm{N}$ stretching vibration was clear evidence of the incorporation of cationic moieties onto the DG chains. This result was also supported by the study conducted by Pal et al. (2005) with the advent of CHPTAC peak at $1400 \mathrm{~cm}^{-1}$ which assigned to the $\mathrm{C}-\mathrm{N}$.

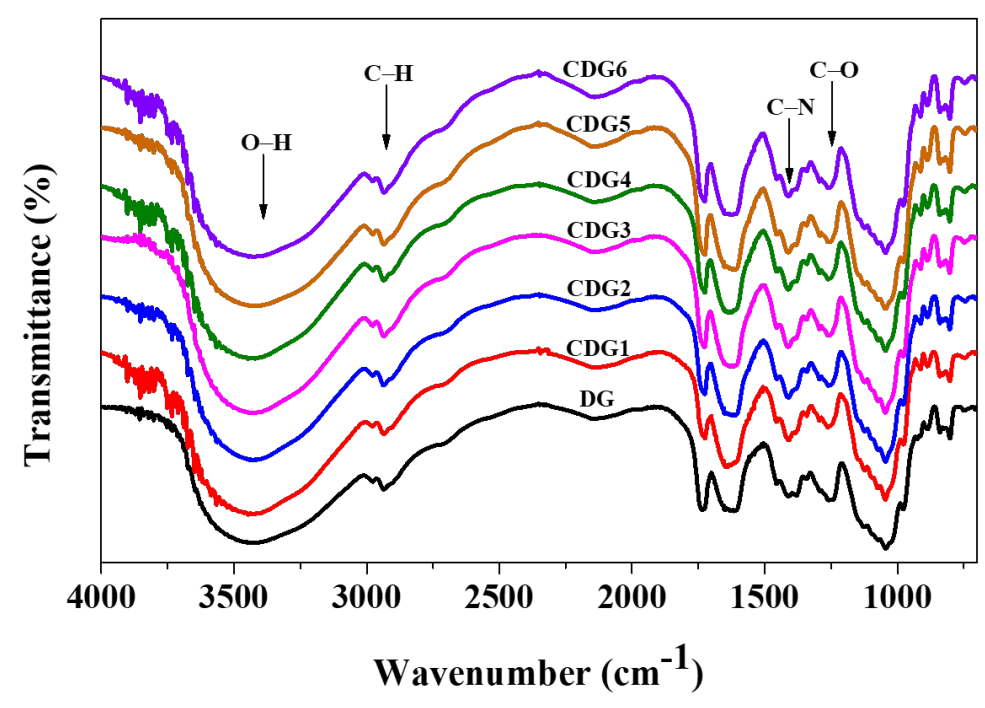

FIGURE 2. FTIR spectra for DG and CDG at different CHPTAC concentration

\section{SURFACE MORPHOLOGY OF DG AND CDG VIA FESEM}

FESEM is an excellent instrument to probe the polysaccharide's morphology. Figure 3(a)-3(g) shows the surface morphology of DG and CDG at various CHPTAC concentrations observed at $5000 \times$ magnification. As shown in Figure 3(a), the DG surface showed a smooth with proper assembled multilayered granular structure. Significant changes were observed on the DG surfaces after CHPTAC modification. For instance, the smooth surface of DG was converted to a connective spherical reticular structure which observed in Figure 3(b). When the CHPTAC concentration increased, the spherical structure was converted into a nearly cubic shape (Figure 3(c)). Further increased in CHPTAC concentration has shown the bigger size cubical shape structure became dominant, not connected, and agglomeration was observed in Figure 3(d)-3(g). Comparing the result with previous studies, cationic modification of polysaccharides showed identical findings on agarose (Prado et al. 2011) and XG (Shi et al. 2017) which showed smooth surface morphology for the native agarose and xanthan. Cationization on the polysaccharides has converted the smooth surface to branched reticular structure and became more remarkable at higher CHPTAC concentration. 

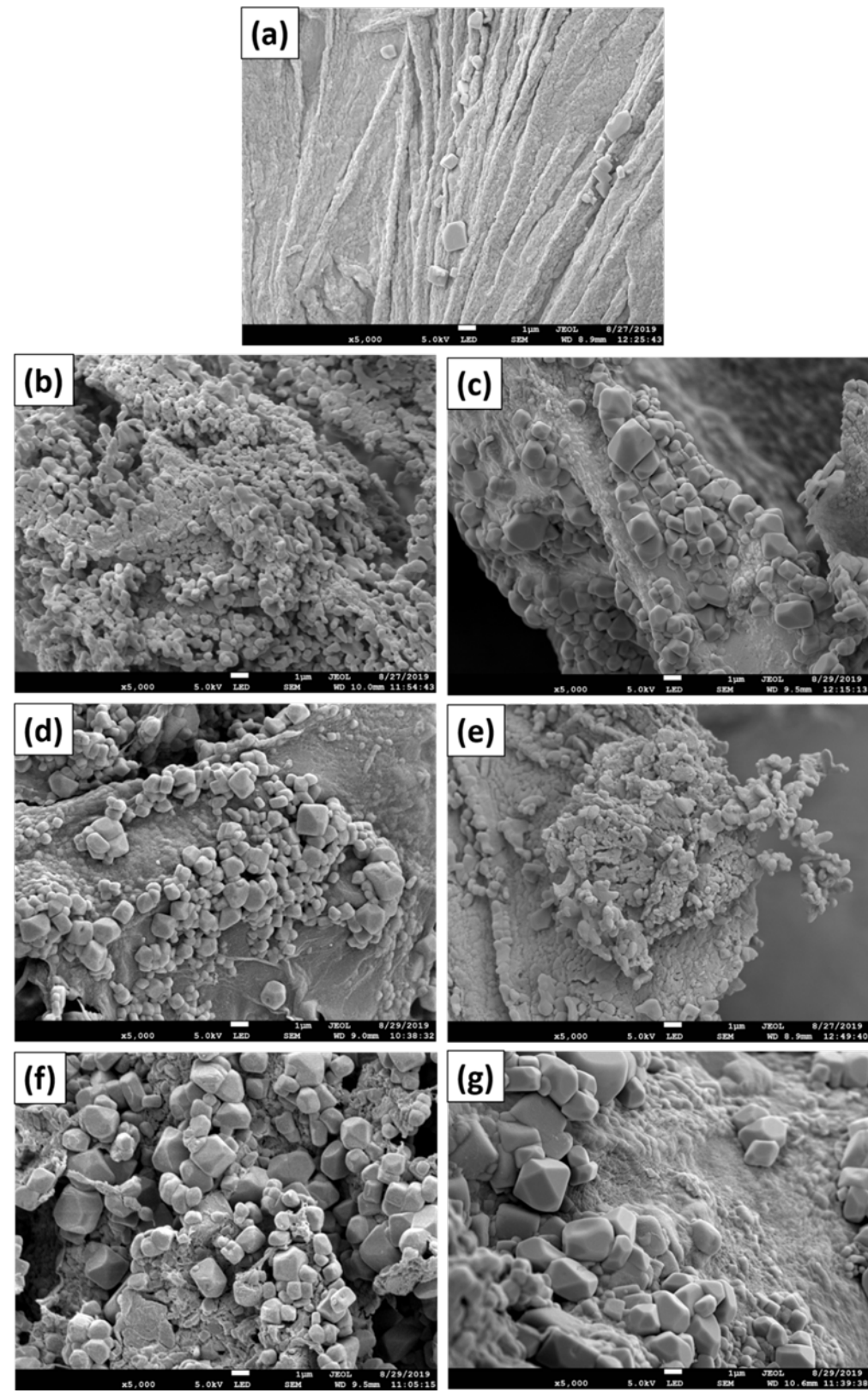

FIGURE 3. FESEM morphology of DG (a) and CDG at various concentrations (b)-(g)

THERMAL PROPERTIES OF DG AND CDG VIA TGA AND DSC

Thermal decomposition of DG and CDG was performed on thermogravimetry analyzer (TGA) in a temperature range from $20-600{ }^{\circ} \mathrm{C}$, as shown in Figure 4 . There are two regions of decomposition have been observed on the TGA thermogram of DG and CDG. The first decomposition has occurred below $100{ }^{\circ} \mathrm{C}$ while the second decomposition happened from 229 to $274{ }^{\circ} \mathrm{C}$. The early decomposition region is attributed to the desorption of physically bound water or moisture from the surface of the DG and CDG. After that, the DG and CDG samples were stable up to $220^{\circ} \mathrm{C}$ before the advent of the second decomposition. The second decomposition was a rapid degradation of all samples with an average weight loss of $\sim 45 \%$ which is due to the decomposition of DG and CDG backbone (Zohuriaan \& Shokrolahi 2004). Incorporation 
of CHPTAC has caused a slight increase in the thermal stability of CDG $\left(256{ }^{\circ} \mathrm{C}\right)$ compared to $\mathrm{DG}\left(250{ }^{\circ} \mathrm{C}\right)$ because of the increased electrostatic attraction between the chains overcoming the mutual repulsion of positive charges of the loaded cationic moiety. The increase in electrostatic attraction hence increases the force to break the chains, which also reported for GG (Pal et al. 2007).

The thermal properties of DG and CDG were further analyzed using DSC to investigate the thermal transitions that occurred on DG after the cationic modification. Figure 5 shows the glass transition temperature $(\mathrm{Tg})$ for the $\mathrm{DG}\left(86^{\circ} \mathrm{C}\right)$ and $\mathrm{CDG}$ in the range of $88-92{ }^{\circ} \mathrm{C}$. The relatively weak and broadened glass transitions can be ascribed to the semi-crystalline nature of the DG and CDG samples. The endothermic peak of CDG was broader compared to DG samples indicated the disintegration of an intramolecular interaction between the amorphous region due to the etherification process (Ren et al. 2007). It was also observed that the Tg peak for CDG was slightly shifted to higher temperature indicating the Tg for the CDGs were improved due to the cationization process which had increased the electrostatic attraction between the chains.

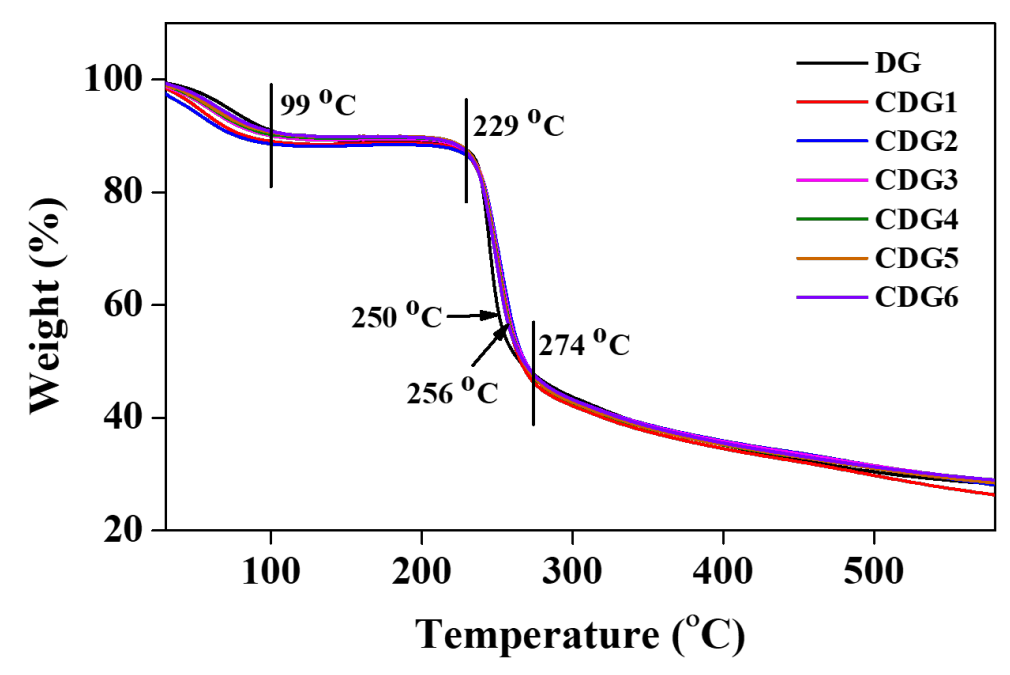

FIGURE 4. TGA weight loss curves for DG and different concentrations of CDG

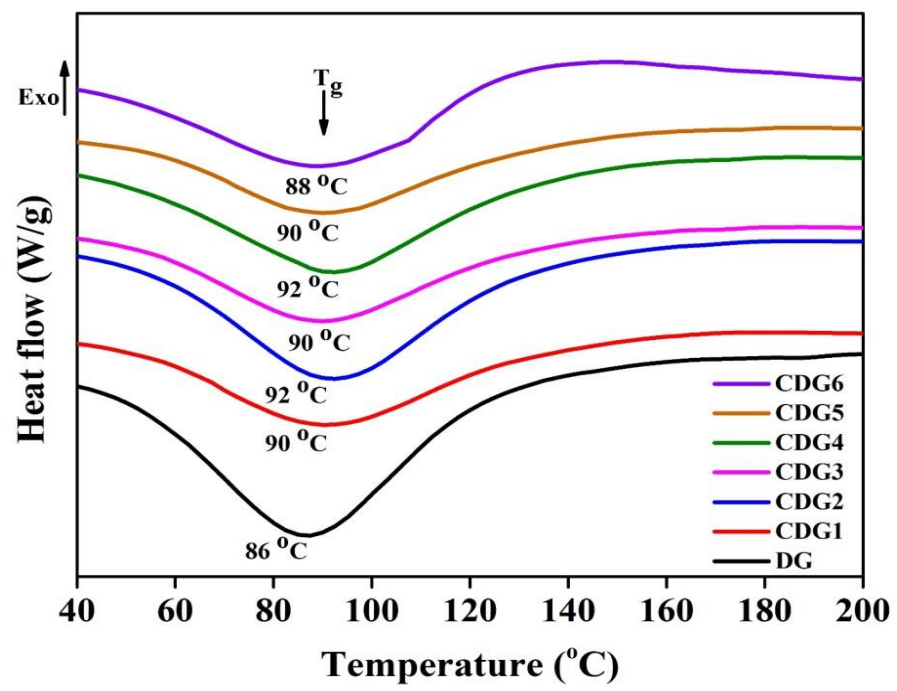

FIGURE 5. DSC curves for the DG and different concentrations of CDG 


\section{RHEOLOGICAL ANALYSIS}

The cationization of DG and CDG has shown an exciting result in terms of viscosity. Table 1 shows the gelling fluid (DG and CDG) viscosity at $25^{\circ} \mathrm{C}$. As shown in Table 1, the DG gelling fluid recorded a viscosity of 104 cP. Cationization had increased the viscosity of CDG1 and CGD 2 by $\sim 10 \%$ to 115 and $112 \mathrm{cP}$, respectively. The modification had offered a sturdy and increase in electrostatic interaction among cationic groups linked to DG and this improved the intertwining network between the chains (Prado et al. 2011; Shi et al. 2017). However, the CDG3, CDG4, CDG5, and CDG6 showed a constant decrement in viscosity. Since the quantity of $\mathrm{NaOH}$ is fixed in this study, therefore, employing higher CHPTAC concentration hindered the CHPTAC substituted on the hydroxyl group of the DG but promoted the agglomeration process. This result was also supported by the morphology observed through FESEM, which increasing CHPTAC concentration produced a bigger cubical structure, not connected and agglomeration. The trend in decreasing viscosity also recorded in the cationization of starch, where the viscosity drop after the optimum monomer concentration is achieved ( $\mathrm{Pal}$ et al. 2005). The dependency between CHPTAC and $\mathrm{NaOH}$ concentration is crucial to achieving the efficiency and maximum degree of substitution. The formation of epoxide and the reacting alkoxides of hydroxyl compound in a polysaccharide are reduced if inadequate of $\mathrm{NaOH}$ is employed. Meanwhile, a surplus amount of $\mathrm{NaOH}$ will lead to epoxide degradation and lowering the molecular weight of the cationized polysaccharide.
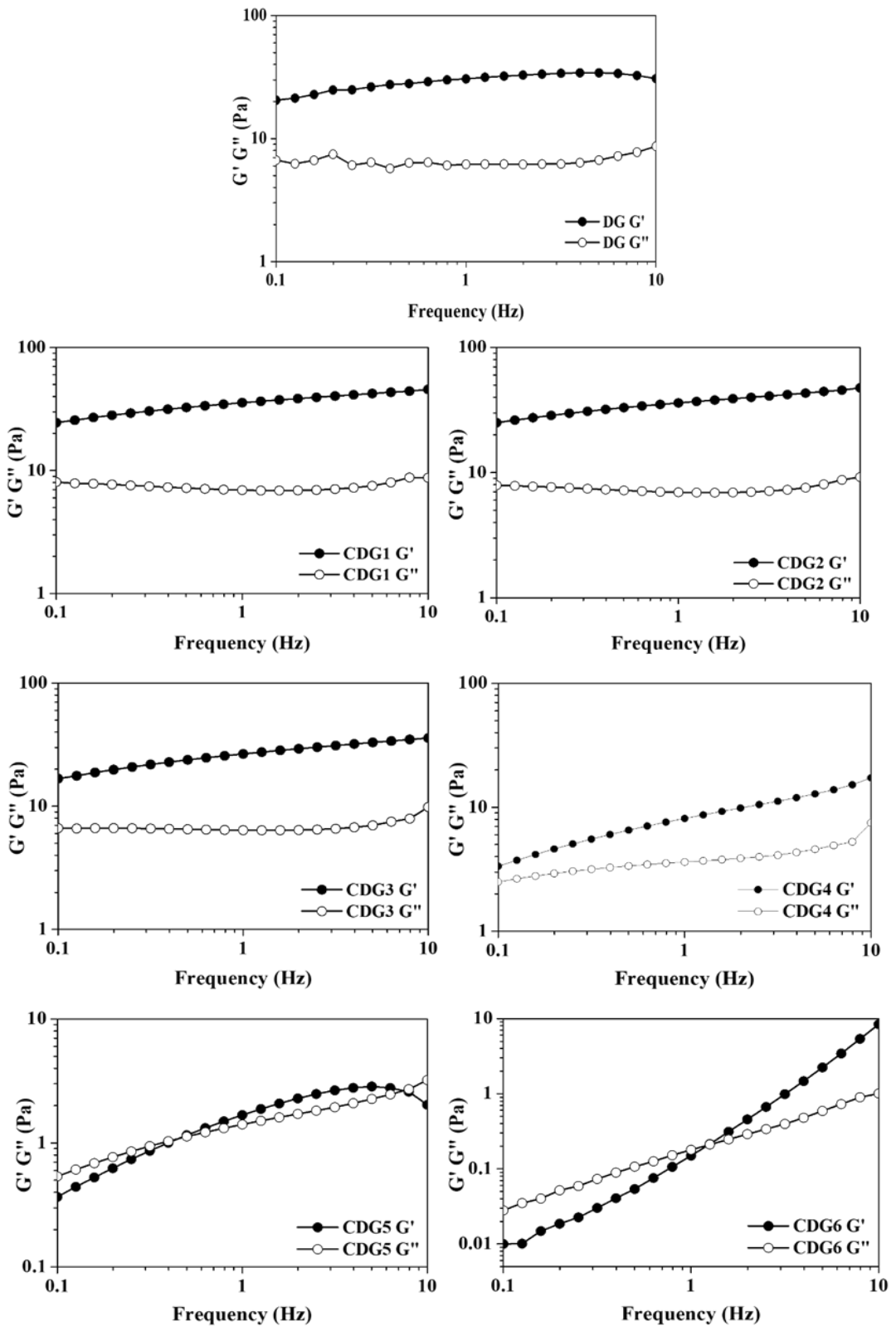

FIGURE 6. The dependence of elastic modulus (G') and viscous modulus (G') of DG and CDG 
A dynamic viscoelasticity measurement test was performed to have a better understanding of the viscoelasticity properties of the DG and CDG gelling fluids. The viscoelasticity test was performed within the determined LVER region to make sure the gelling fluidstructure did not damage when the force is imposed during the testing. The state of the polymer gel strongly influences the rheological properties of the gelling fluid. According to Deshpande (2009), a highly concentrated gelling fluid will show a gel-like response, inferring dynamic elastic modulus $\left(\mathrm{G}^{\prime}\right)$ to be higher than viscous modulus $\left(\mathrm{G}^{\prime \prime}\right)$ and both being almost constant concerning frequency (Deshpande 2009). A viscous liquid or lower concentrated gelling fluid will show a crossover point between $\mathrm{G}^{\prime}$ and $\mathrm{G}^{\prime \prime}$. This crossover frequency is associated with a relaxation time characteristic for the onset of the terminal or flow region for the fluid. The dependence of the G' and G" on the oscillation frequency for DG and CDG gelling fluid are shown in Figure 6. As shown in the rheogram, the $\mathrm{G}^{\prime}$ is larger than $\mathrm{G}^{\prime \prime}$ for DG, CDG1, CDG2, CDG3, and CDG4 and no crossover was observed. The DG spectra can be confirmed by several previous studies (Arbaa'in et al. 2018; Carmen García González et al. 2019). A plateau-like region was seen which signifying a stable gel response towards the frequency due to the interaction of the neighboring DG or CDG biopolymers ( $\mathrm{Li}$ et al. 2012). There is a slight increase in CDG viscoelasticity (CDG with optimum $\mathrm{NaOH}$ concentration) after the incorporation of the CHPTAC. The same was reported for XG after cationization (Shi et al. 2017). In the case of CDG5 and CDG6, the $G$ " is higher compared to $G^{\prime}$, indicating the viscous modulus is dominating in the oscillation frequency. A crossover was also observed at frequency $\sim 0.5$ and $\sim 1.0$ $\mathrm{Hz}$, respectively. Therefore, the CDG5 and CDG6 are behaving as a viscous liquid while the others exhibit the gel-like properties (Xu et al. 2019). In addition, the G' and G" trend was also increased as the frequency increased which indicative of a weak gel-like structure (Covis et al.
2016). The term weak gel is defined as the material that has an infinite viscosity and simultaneously has a vanishing equilibrium shear modulus. The properties of the strong gel should have G'> G' and nearly independent toward a wide frequency range (Douglas 2018).

\section{EFFECT OF TEMPERATURE ON VISCOSITY OF DG AND CDG GELLING FLUID TESTED USING STATIC AGING TEST}

The effect of temperature on the viscosity of DG and CDG has been investigated, as shown in Figure 7. CDG2 gelling fluid has been selected and compared with DG gelling fluid as it produced stable viscosity among other CDGs. Both gelling fluid were fixed in a closed-system autoclave to avoid evaporation and heated in the range of $100-180{ }^{\circ} \mathrm{C}$ using an oven for a static aging test. The viscosity recorded after the static aging test showed that both samples were stable up to $160{ }^{\circ} \mathrm{C}$ with $\mathrm{CDG} 2$ has higher viscosity compared to DG. The fluids were stable because of the excellent water retention ability owing to the double-helical molecular structures of the DG and CDG2. This ability also exerts strong internal force and manages to maintain fluid viscosity upon high-temperature exposure (Tako 1994). As the temperature increased to $170{ }^{\circ} \mathrm{C}$, both DG and CDG2 viscosity begin to decline by 11 and $8 \%$, respectively. At this temperature, the motions of the molecules have accelerated and decrease the van der Waals forces and hydrogen bond. Hence, it decreased the entanglements of macromolecules and weakened the gelling fluids network (Liang et al. 2019). Observation made on both samples showed that CDG has slightly less deteriorated as it managed to maintain the doublehelical structure compare to the DG. This is because the increase in elasticity and electrostatic interaction between the CDG2 chains after the cationization has increased its tolerance toward temperature compared with DG. At 180 ${ }^{\circ} \mathrm{C}$, a massive viscosity decrement was observed due to the breaking of the gelling fluid network.

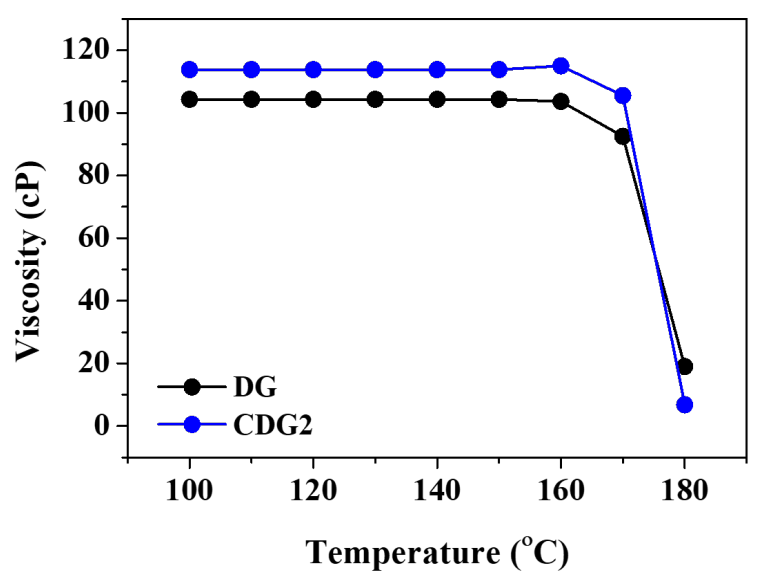

FIGURE 7. Effect of temperature on the viscosity of DG and CDG 


\section{CONCLUSION}

DG has been successfully modified with different concentrations of CHPTAC. Cationic modification on DG using CHPTAC was proved with the appearance of a new peak at $1406 \mathrm{~cm}^{-1}$ attributed to the $\mathrm{C}-\mathrm{N}$ stretching vibration on the IR spectrum. An increasing viscosity was observed at a low concentration of CHPTAC but decreased after further addition of CHPTAC. The viscosity supposed to be increased as the amount of CHPTAC increased. Nevertheless, this phenomenon is only possible if the optimum concentration of $\mathrm{NaOH}$ in each case was employed. Rheological properties showed that the plateau-like region was observed which signifying a stable gel response towards frequency due to $G^{\prime}$ is larger than $G^{\prime \prime}$ for DG and CDG. The viscosity recorded after the static aging test showed that both samples were stable up to $170{ }^{\circ} \mathrm{C}$ suggesting these biopolymers can withstand the high-temperature requirements of the upstream petroleum industry. The DG and CDG gelling fluid are not sensitive to the temperature as it is stabilized by the disaccharide side chains and cationic moiety.

\section{ACKNOWLEDGEMENTS}

The authors gratefully acknowledge financial support provided by Universiti Malaysia Pahang under grant no. of RDU170327 and RDU190330. Exceptional thanks to the Centre of Excellence for Advanced Research in Fluid Flow (CARIFF) for their laboratory facilities.

\section{REFERENCES}

Abbas, S., Sanders, A.W. \& Donovan, J.C. 2013. Applicability of hydroxyethylcellulose polymers for chemical EOR. SPE Enhanced Oil Recovery Conference Publication No. 165311-MS. April 20-23.

Arbaa'in, N., Roslan, R., Ismail, J., Ab Rahim, M.H. \& Mohd Tahir, F.K. 2020. The study of cationic modification of welan gum. Materials Science Forum 981: 127-131.

Arbaa'in, N., Roslan, R., Ismail, J. \& Rahim, M.H.A. 2018. Modification of diutan gum to enhance rheological properties for oil and gas application. AIP Conference Proceedings 2030(1): 020218.

Bai, Y., Shang, X., Wang, Z. \& Zhao, X. 2018. Experimental study on hydrophobically associating hydroxyethyl cellulose flooding system for enhanced oil recovery. Energy \& Fuels 32(6): 6713-6725.

Banerjee, P., Mukherjee, I., Bhattacharya, S., Datta, S., Moulik, S.P. \& Sarkar, D. 2009. Sorption of water vapor, hydration, and viscosity of carboxymethylhydroxypropyl guar, diutan, and xanthan gums, and their molecular association with and without salts $\left(\mathrm{NaCl}, \mathrm{CaCl}_{2}, \mathrm{HCOOK}, \mathrm{CH}_{3} \mathrm{COONa}\right.$, $\left(\mathrm{NH}_{4}\right)_{2} \mathrm{SO}_{4}$ and $\mathrm{MgSO}_{4}$ ) in aqueous solution. Langmuir 25(19): 11647-11656.
Barnes, J.R., Smit, J., Smit, J., Shpakoff, G., Raney, K.H. \& Puerto, M. 2008. Development of surfactants for chemical flooding at difficult reservoir conditions. SPE Symposium on Improved Oil Recovery Publication No. 113313-MS. April 20-23.

Carmen García González, M., Del Socorro Cely García, M., García, J.M. \& Alfaro-Rodriguez, M.C. 2019. A comparison of the effect of temperature on the rheological properties of diutan and Rhamsan gum aqueous solutions. Fluids 4(1): 22.

Castillo, N.A., Valdez, A.L. \& Fariña, J.I. 2015. Microbial production of scleroglucan and downstream processing. Frontiers in Microbiology 6(2015): 1106.

Chen, Q., Wu, Y., Pu, Y., Zheng, Z., Shi, C. \& Huang, X. 2010. Synthesis and characterization of quaternized $\beta$-chitin. Carbohydrate Research 345(11): 1609-1612.

Covis, R., Guegan, J.-P., Jeftić, J., Czjzek, M., Benoit, M. \& Benvegnu, T. 2016. Structural and rheological properties of kappa $(\kappa)$-carrageenans covalently modified with cationic moieties. Journal of Polymer Research 23(4): 78.

Deshpande, A. 2009. Techniques in Oscillatory Shear Rheology. https://www.semanticscholar.org/paper/Techniques-inoscillatory-shear-rheology-Deshpande/6614c4224df77eb 1615beb0aca1e580511022354.

Diltz, S. \& Zeller, S.G. 2001. Location of O-acetyl groups in S-657 using the reductive-cleavage method. Carbohydrate Research 331(3): 265-270.

Douglas, J.F. 2018. Weak and strong gels and the emergence of the amorphous solid state. Gels 4(1): 19 .

Fariña, J.I., Siñeriz, F., Molina, O.E. \& Perotti, N.I. 2001. Isolation and physicochemical characterization of soluble scleroglucan from Sclerotium rolfsii. Rheological properties, molecular weight and conformational characteristics. Carbohydrate Polymers 44(1): 41-50.

Gao, C. 2016. Application of a novel biopolymer to enhance oil recovery. Journal of Petroleum Exploration and Production Technology 6(4): 749-753.

Gao, C. 2015. Potential of Welan gum to enhance oil recovery. Journal of Petroleum Exploration and Production Technology 5(2): 197-200.

Ghimici, L., Morariu, S. \& Nichifor, M. 2009. Separation of clay suspension by ionic dextran derivatives. Separation and Purification Technology 68(2): 165-171.

Haack, V., Heinze, T., Oelmeyer, G. \& Kulicke, W.M. 2002. Starch derivatives of high degree of functionalization, synthesis and flocculation behavior of cationic starch polyelectrolytes. Macromolecular Materials and Engineering 287(8): 495-502.

Jang, H.Y., Zhang, K., Chon, B.H. \& Choi, H.J. 2015. Enhanced oil recovery performance and viscosity characteristics of polysaccharide xanthan gum solution. Journal of Industrial and Engineering Chemistry 21: 741-745.

Jo, J., Okazaki, A., Nagane, K., Yamamoto, M. \& Tabata, Y. 2010. Preparation of cationized polysaccharides as gene transfection carrier for bone marrow-derived mesenchymal stem cells. Journal of Biomaterials Science. Polymer Edition 21(2): 185-204. 
Kavaliauskaite, R., Klimaviciute, R. \& Zemaitaitis, A. 2008. Factors influencing production of cationic starches. Carbohydrate Polymers 73(4): 665-675.

Li, H., Chen, R., Lu, X. \& Hou, W. 2012. Rheological properties of aqueous solution containing xanthan gum and cationic cellulose JR400. Carbohydrate Polymers 90(3): 1330-1336.

Li, Y., Xu, L., Gong, H., Ding, B., Dong, M. \& Li, Y. 2017. A microbial exopolysaccharide produced by Sphingomonas species for enhanced heavy oil recovery at high temperature and high salinity. Energy \& Fuels 31(4): 3960-3969.

Liang, K., Han, P., Chen, Q., Su, X. \& Feng, Y. 2019. Comparative study on enhancing oil recovery under high temperature and high salinity: Polysaccharides versus synthetic polymer. ACS Omega 4(6): 10620-10628.

Marques, N.d.N., d.C.B., Rosalenga, Halila, S. \& Borsali, R. 2018. Synthesis and characterization of carboxymethylcellulose grafted with thermoresponsive side chains of high LCST: The high temperature and high salinity self-assembly dependence. Carbohydrate Polymers 184: 108-117.

Moral, A., Aguado, R. \& Tijero, A. 2016. Alkalization and cationization of cellulose: Effects on intrinsic viscosity. Fibers and Polymers 17(6): 857-861.

Pal, S., Mal, D. \& Singh, R.P. 2007. Synthesis and characterization of cationic guar gum: A high performance flocculating agent. Journal of Applied Polymer Science 105(6): 32403245 .

Pal, S., Mal, D. \& Singh, R.P. 2005. Cationic starch: An effective flocculating agent. Carbohydrate Polymers 59(4): 417-423.

Prado, H.J. \& Matulewicz, M.C. 2014. Cationization of polysaccharides: A path to greener derivatives with many industrial applications. European Polymer Journal 52(1): 53-75.

Prado, H.J., Matulewicz, M.C., Bonelli, P.R. \& Cukierman, A.L. 2011. Studies on the cationization of agarose. Carbohydrate Research 346(2): 311-321.

$\mathrm{Pu}, \mathrm{W}$., Shen, C., Wei, B., Yang, Y. \& Li, Y. 2018. A comprehensive review of polysaccharide biopolymers for enhanced oil recovery (EOR) from flask to field. Journal of Industrial and Engineering Chemistry 61: 1-11.

Ren, J.L., Sun, R.C., Liu, C.F., Lin, L. \& He, B.H. 2007. Synthesis and characterization of novel cationic SCB hemicelluloses with a low degree of substitution. Carbohydrate Polymers 67(3): 347-357.

Ryles, R.G. 1988. Chemical stability limits of water-soluble polymers used in oil recovery processes. SPE Reservoir Engineering 3(1): 23-34.

Shi, L., Wei, Y., Luo, N., Tan, T. \& Cao, H. 2017. The rheological and thickening properties of cationic xanthan gum. Journal of Dispersion Science and Technology 39(1): 55-61.

Sonebi, M. 2006. Rheological properties of grouts with viscosity modifying agents as diutan gum and welan gum incorporating pulverised fly ash. Cement and Concrete Research 36(9): 1609-1618.

Sonebi, M. \& McKendry, D. 2008. Effect of mix proportions on rheological and hardened properties of composite cement pastes. The Open Construction and Building Technology Journal 2(1): 15-23.

Tako, M. 1994. Molecular origin for the thermal stability of S-657 polysaccharide produced by Xanthomonas ATCC 53159. Polymer Gels and Networks 2(2): 91-104.

Tarus, D., Hachet, E., Messager, L., Catargi, B., Ravaine, V. \& Auzély-Velty, R. 2014. Readily prepared dynamic hydrogels by combining phenyl boronic acid- and maltose-modified anionic polysaccharides at neutral $\mathrm{pH}$. Macromolecular Rapid Communications 35(24): 2089-2095.

Tian, D., Wu, X., Liu, C. \& Xie, H.Q. 2010. Synthesis and flocculation behavior of cationic konjac glucomannan containing quaternary ammonium substituents. Journal of Applied Polymer Science 115(4): 2368-2374.

Wang, S., He, L., Guo, J., Zhao, J. \& Tang, H. 2015. Intrinsic viscosity and rheological properties of natural and substituted guar gums in seawater. International Journal of Biological Macromolecules 76(Supplement C): 262-268.

Wang, Z.H., Li, W.B., Ma, J., Tang, G.P., Yang, W.T. \& Xu, F.J. 2011. Functionalized nonionic dextran backbones by atom transfer radical polymerization for efficient gene delivery. Macromolecules 44(2): 230-239.

Xu, L., Qiu, Z., Gong, H., Zhu, C., Li, Z., Li, Y. \& Dong, M. 2019. Rheological behaviors of microbial polysaccharides with different substituents in aqueous solutions: Effects of concentration, temperature, inorganic salt and surfactant. Carbohydrate Polymers 219: 162-171.

Xu, L., Gong, H., Dong, M. \& Li, Y. 2015. Rheological properties and thickening mechanism of aqueous diutan gum solution: Effects of temperature and salts. Carbohydrate Polymers 132: 620-629.

Yu, H., Huang, Y., Ying, H. \& Xiao, C. 2007. Preparation and characterization of a quaternary ammonium derivative of konjac glucomannan. Carbohydrate Polymers 69(1): 29-40.

Zhang, J., Weissinger, E.A., Peethamparan, S. \& Scherer, G.W. 2010. Early hydration and setting of oil well cement. Cement and Concrete Research 40(7): 1023-1033.

Zhou, H., Deville, J.P. \& Davis, C.L. 2015. Novel high density brine-based drill-in fluids significantly increased temperature limit for HP/HT applications. Society of Petroleum Engineers. SPE/IADC Drilling Conference and Exhibition Publication No. 173075-MS. March 17-19.

Zohuriaan, M.J. \& Shokrolahi, F. 2004. Thermal studies on natural and modified gums. Polymer Testing 23(5): 575-579.

Faculty of Industrial Sciences and Technology

Universiti Malaysia Pahang

26300 Gambang, Kuantan, Pahang Darul Makmur Malaysia

*Corresponding author; email: rasidi@ump.edu.my

Received: 7 February 2020

Accepted: 19 April 2020 